\title{
Power system balancing of North Sea countries with large share of wind power
} towards 2050

\author{
Kaushik Das ${ }^{1}$, Juan Gea-Bermúdez ${ }^{1,2}$, Polyneikis Kanellas ${ }^{1}$, Matti Koivisto ${ }^{1}$, \\ Juan Pablo Murcia Leon ${ }^{1}$, Poul Ejnar Sørensen ${ }^{1}$
}

\begin{abstract}
Increasing share of renewables poses new challenges towards planning and operation of power systems all over the world, thereby, requiring new methods and tools. This article explains the value of balancing tool chain which encompasses operation of market and power system from day-ahead planning until the real-time dynamic simulation. The salient features for such a balancing tool chain is discussed in this article. A Balancing Tool Chain has been developed and validated based on balancing principles of Denmark and Europe. The efficacy of the balancing tool chain is demonstrated through very detailed case studies of massive penetration of offshore wind power in North Sea countries towards 2050. Using detailed case studies, recommendations are provided towards balancing of North Sea countries in terms of operational and balancing practices as well as dimensioning of reserves for future scenarios.
\end{abstract}

\section{Index Terms}

Balancing, Frequency, Reserves, Uncertainty, Variability, Wind Power

\section{INTRODUCTION}

The share of renewable energy sources (RES) in traditional electrical power systems has been increasing all over the world in the last decades mainly to meet environmental needs, energy security concerns and sustainable development goals. Many of these RES sources are inherently variable in nature and can be categorised as variable renewable energy (VRE) sources. Among these VRE sources, costs of wind power generation and solar power generation technologies have been drastically reducing at the same time, making them the preferred electricity generation options in the positive direction of de-carbonised energy systems all over the world. Europe has been among the leaders in installation and integration of wind and solar power to the grid. The European commission has vision of reducing carbon emission by $100 \%$ by 2050 [1]. In this direction, there are efforts and plans for massive installations of offshore wind power plants (OWPP) mainly in North Sea and Baltic Sea owing

Kaushik Das(kdas@dtu.dk), Polyneikis Kanellas, Matti Koivisto, Poul Ejnar Sørensen and Juan Pablo Murcia Leon are with DTU Wind Energy, Technical University of Denmark, Ris $\varnothing$, Frederiksborgvej 399, 4000 Roskilde, Denmark.

Juan Gea-Bermúdez is with the Department of Management, Technical University of Denmark (DTU), Produktionstorvet, Bygning 426, 2800 Kongens Lyngby, Denmark. 
to low sea depth. Massive penetration of such OWPPs will heavily impact the power flow in the interconnected European power systems, which has rendered the requirement for installation of new long distance transmission lines such as the Viking link between Denmark and Great Britain. However, owing to the inherent variable nature of wind power and the uncertainty in forecasts, operation and operational planning of power systems are challenged in terms of security and stability of the power system. One of such major challenge is estimating and allocating reserves to mitigate the impact of imbalances created by forecast uncertainty of RES. These operating reserves can be in the form of cheaper and slower balancing reserves as well as expensive and faster manual or automatic frequency reserves. Traditionally, these reserves have been acquired from conventional generation sources such as coal-fired thermal or hydro generators. However, more and more of fossil fuel based generations are being replaced by RES, thereby, depleting the reserve resources as well. It is eminent that RES should take more responsibilities in future power systems in providing active power reserves as grid services.

Simultaneously, there are major challenges in assessment of availability of reserves and success of balancing process in future power systems which operate with large share of variable RES in a highly uncertain environment. Balancing principles lie in the fact that the closer to the time of operation, the lower the forecast uncertainty of the VRE generations is, which allows for improved decision making by the operators. Balancing involve several processes and entities ranging from seconds to days timescale. Automatic reserves are generally ascertained before the day-ahead spot energy market. However, the market trading at the day-ahead spot market dictates which technologies and the amount of balancing reserve that might be available in the real-time. Whereas intra-day market allows for handling unforeseen imbalances (such as arising due to contingencies) during the day of operation. However, the transmission system operator (TSO) has the opportunity to utilize balancing reserves few minutes to an hour before the operation to mitigate the imbalances generally arising from the uncertainties of generations and loads. The remaining imbalances are handled by frequency reserves in real-time. Therefore, in order to assess the efficacy of balancing process, all these sub-processes need to be analysed separately and as well as in conjunction. Traditional methodologies and tools which perform such assessments need to be either redeveloped or updated in order to meet all the salient features of the balancing process, more so, in power system with high shares of RES.

There are several analytical methods and tools for assessment of power balancing [2]. Kermit [3] is DNV GL's proprietary simulation tool which can simulate power system frequency behaviour ranging from $1 \mathrm{~s}$ to 24 hours. However, it does not include intra-hour balancing process as well as detailed spot market analysis. Forecast error uncertainty are also not considered in this tool. Advance dispatching tool [4] developed by Terna and CESI is very suitable for short-term adequacy studies, however, balancing market is not considered in details. Similarly, there are many tools and methodologies available which are mainly focused for individual subprocess but cannot provide detailed assessment of the complete balancing process. Different unit commitment methodologies [5] and economic dispatch methods [6] for spot market simulation have been developed in literature. In terms of tools, there are several tools for spot market analysis such as Balmorel [7], Wilmar [8], SIFRE [9], etc. Similarly, there are many methods regarding balancing markets [10], [11] as well as frequency reserves estimation [12] and deployment. Mileva et. al. [13] describe operations and balancing requirements for Western Electricity Coordinating Council power system for the purpose of deep decarbonisation. However, the methodology does not include the studies on the impact of forecast error and neither the dynamic balancing 
requirements. However, all these methods or tools handle only individual sub-process and not all the subprocesses as mentioned before. However, not able to run all the balancing processes has many disadvantages, mainly because the dependencies between the sup-processes are not captured. To authors' knowledge, there is no single tool/tool chain which connects all these tools to assess the quality of balancing of large power system with high share of renewables. Therefore, DTU has developed a tool chain that encompasses all these processes. The contribution of this paper is as following:

- Salient features are described showing the advantages and necessities of balancing tool chain as opposed to individual sub-process.

- Balancing tool chain is described explaining all the sub-processes in details. The focus in this paper is for mitigating the impact of forecast uncertainties from wind power; however, the methods described are generic and can be applied to quantify the impact of any forecast uncertainties.

- Case studies are performed for application of DTU balancing tool chain for very large Northern European power system for 2020, 2030 and 2050 scenarios. Energy scenarios of North Sea countries are modelled with massive installation of OWPPs in North Sea.

- Recommendations are provided for balancing requirements (with main focus in Denmark) for these future scenarios for different methods of connecting OWPPs to the power system (Project-based and Offshore Grid).

The paper is structured as following. Section II lists all the salient features of balancing tool chain. Section III explains the DTU Balancing Tool Chain. Case studies and results are provided in section IV. Section V concludes the paper.

\section{SAlient FEAtures of Balancing Tool Chain}

Running all the sup-processes of balancing process in tandem has many advantages. The salient features of the Balancing Tool Chain together with the advantages of these features are listed below:

- For assessment of any power system with large share of weather dependent VRE, weather models play huge role. Same weather model or reanalysis runs should drive all the sub-processes of balancing methodology, otherwise there can be large inaccuracies in the estimation of weather based generations.

- Knowledge of one sub-process is very important to another sub-process, therefore dependencies of each sub-process with respect to other sub-process needs to be modelled. As more and more RES replaces conventional generations, it impacts the mix of generations at different operating conditions. For example, if the forecast for RES is high, it can imply that not many conventional generation will be online based on spot market bidding. Therefore, it will reduce the system inertia (as well as spinning reserve) and impact on the specifications for frequency reserve activation. Further, it also decides the balancing reserves available from the online generations and need for fast start-up generations to provide balancing services. This is also important for adequacy planning. For example, not considering fast ramp requirements required for balancing and frequency reserves, during spot market analysis might lead to inaccurate operational planning.

- Same weather model should be used to simulate time series for different types of VRE and loads to consider spatio-temporal correlations between the sources. Weather resource to power conversion for each 
technology depends on multiple factors. For example - wind power generation depends on wind turbine technology parameters as well as fluctuations in wind resources. Additionally, wakes (both intra-farm and farm to farm wakes) can have large impact in terms of reduced energy production from wind power plants. Storm protection features of the wind power plants is another important criteria to be included especially for power system balancing studies [14]. Similarly, for solar power simulation, fluctuations and uncertainties in solar resource as well as solar technology (PV vs CSP, tracking vs stationary, monofacial vs bifacial) need to be considered.

- Balancing reserve and frequency reserve requirements should be considered in spot market analysis.

- Balancing tool chain should consider not only the concerned control area but also neighboring control areas. Control areas in large interconnected power systems with high share of RES are expected to get support from neighboring regions mainly pertaining to geographical smoothing of RES fluctuations.

- Balancing tool chain should not only consider electricity sector but also other interrelated sectors such as transport, heating sectors. These sectors can have constraints in terms of ramping capabilities as well as volume of reserve.

\section{BALANCING TOOL CHAin}

Figure 1 shows a generic diagram of balancing tool chain (based on operating principle of Nordic power system) with sub-processes activated at different time of the day until the time of operation. It should be noted that one or other of the sub-processes might be activated or not depending on the power system being studied for. This tool chain is shown as feed-forward since that is the natural flow of signals consistent with the timeline. However, there are feedback from the sub-processes as well, although the feedback can be periodic ranging from once every day to once every year, depending on the specification of the feedback signal.

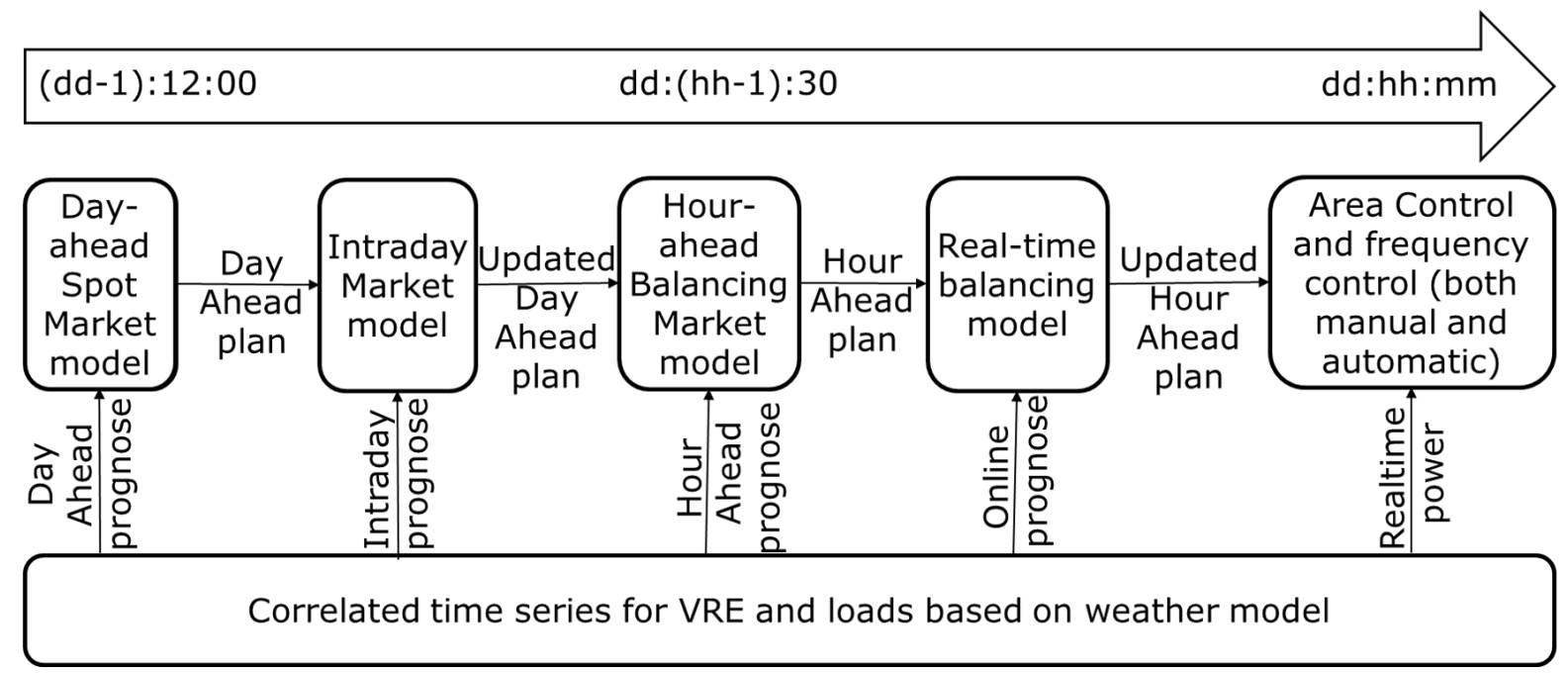

Fig. 1. Balancing Tool Chain

The balancing tool chain can be used by system operators, energy planners, power plant developers, consultants, researchers for following applications among many others: 
- Quantification of variability in VRE generations considering spatio-temporal correlations as well as technology characteristics.

- Analysis of the impact of VRE forecast error on imbalance in the power system.

- Estimation and assessment of reserve requirements for different degree of RES penetration.

- Estimation of power system parameters such as inertia and damping for power systems with high share of RES.

- Assessment of cost of electricity for future power systems for feasibility studies of future projects.

- Selection of technologies for reserve provisions based on the ramping of the RES generations.

- Analysis of impact of policies such as $\mathrm{CO} 2$ prices on power system operation as well as market prices.

- Analysis of impact of electrification of different sectors on balancing requirements of the power system.

- Adequacy planning for generations and transmission for future power systems with large share of RES.

Many of these capabilities are exemplified with the case study in a later section of the article. DTU Balancing

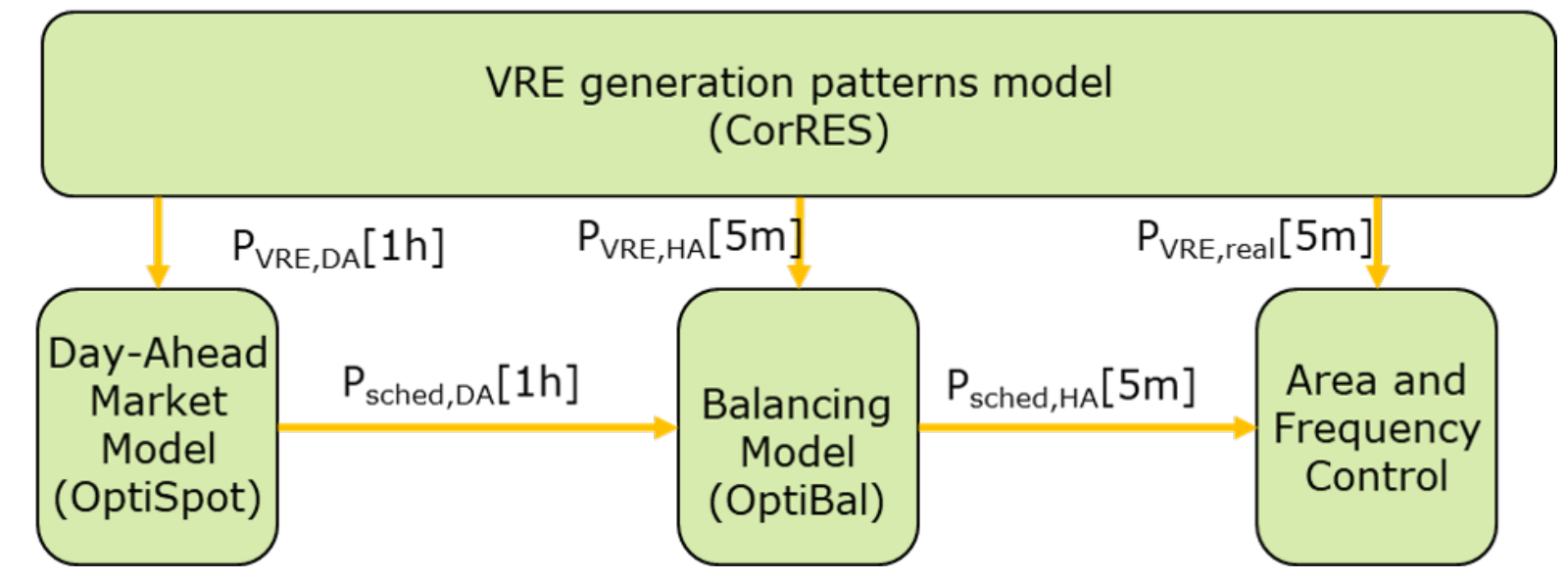

Fig. 2. DTU Balancing Tool Chain

Tool Chain as shown in Fig. 2 has the sup-processes of VRE generation patterns model, Day-ahead spot market model, Hour-ahead balancing model, area and frequency control model. This article only provides the overviews of these sub-processes for the sake of better explaining the case studies.

\section{A. Correlated time series generation for VRE - CorRES}

CorRES [15], [16] is used for simulating the wind and solar available power and forecast time series. The meteorological year 2012 has been chosen as the reference year for weather modelling, as it matches the load data in OptiSpot. The stochastic simulation part in CorRES [17] is applied to capture the high frequency variability in offshore wind generation. Modelling of expected VRE technology development is included, with increasing capacity factors towards 2050 [18]. Wake modelling between different offshore wind farms has been implemented which can either be switched on or off depending on the application. Engineering wake models implemented in PyWake [19] are used to generate wind direction dependent plant power curves that reflect the impact of intra-farm wake losses and farm-to-farm wake losses from nearby plants. The simulation of wind forecast errors in CorRES is carried out using a vector autoregressive model based on [20]. Solar forecast errors 
are not considered in the presented case study, as the solar forecast error simulation model was not available for all analysed countries when the analyses were carried out.

\section{B. Day-ahead spot market model - OptiSpot}

OptiSpot is modelled in the Balmorel energy system model [7] in this paper to model the day-ahead market for both electricity and heating sector with 24 hour foresight. Mathematical modelling and analysis can be found in [21]. Market models are developed for each market area of the North Sea countries. In this paper, the model is used with relaxed mixed integer programming. The model is coded in GAMS with CPLEX used as solver for optimization. The objective function is to minimize the operational costs of the power system for every time step of 1 hour. The costs include fixed operational and maintenance costs, variable operational and maintenance costs, unit commitment related costs, emission tax costs, and transmission use costs. The main constraint of the electricity sector is the hourly electricity balance, in which the use of the electricity storage is optimized, and where most of the electricity demand is considered inelastic, except for the use of electricity to heat in district heating networks. Other constraints involve ramping rates of the generators involved in the balancing market. The details of these costs and constraints can be found in [22]. The heat balance is also modelled.

\section{Hour Ahead Balancing Market Model - OptiBal}

OptiBal is modelled in Balmorel to simulate the balancing market. This mode of using Balmorel is defined in this paper as OptiBal. OptiBal is modelled based on Danish balancing principle used in Energinet's tool SimBa [10]. However, contrary to SimBa's heuristic methods; a mathematical optimization method is developed as detailed in [22]. The principle of the hour-ahead balancing lies in the fact that since the day-ahead planning used day-ahead forecast and as hour-ahead forecast is received, there is a mismatch between day-ahead and hour-ahead forecast. This mismatch is the estimated imbalance which can be mitigated by re-dispatching the units of the system to guarantee the energy balance and minimize costs. Available cheap balancing reserve will be used first, otherwise expensive automatic reserves will be utilized to mitigate the imbalance and also depreciating the automatic reserves meant for handling large contingencies. It is important to note that this is the balancing principle used by Danish TSO - Energinet. However, in this article all the neighboring control areas are also modelled to have the same balancing principles which may vary from country to country. The optimization is very similar to that of day-ahead optimization but with some key differences. In OptiBal a time step resolution of 5 minutes with 1 hour foresight is used. The commitment of slow units, i.e. those units who can't start-up, shut-down, ramp-up, or ramp-down in 1 hour (the assumed foresight) is fixed from the Day-ahead dispatch. Storage use is modelled with the updated economic value of its content from the day-ahead run, which means that storage units could deviate from the day-ahead schedule if it is found profitable.

\section{Area and frequency control}

Controls are developed in Matlab Simulink based on control philosophies and principles of the Nordic Network as shown in Fig. 3 and the Continental European (CE) network as shown in Fig. 4 as described in [22], [23], [12]. 


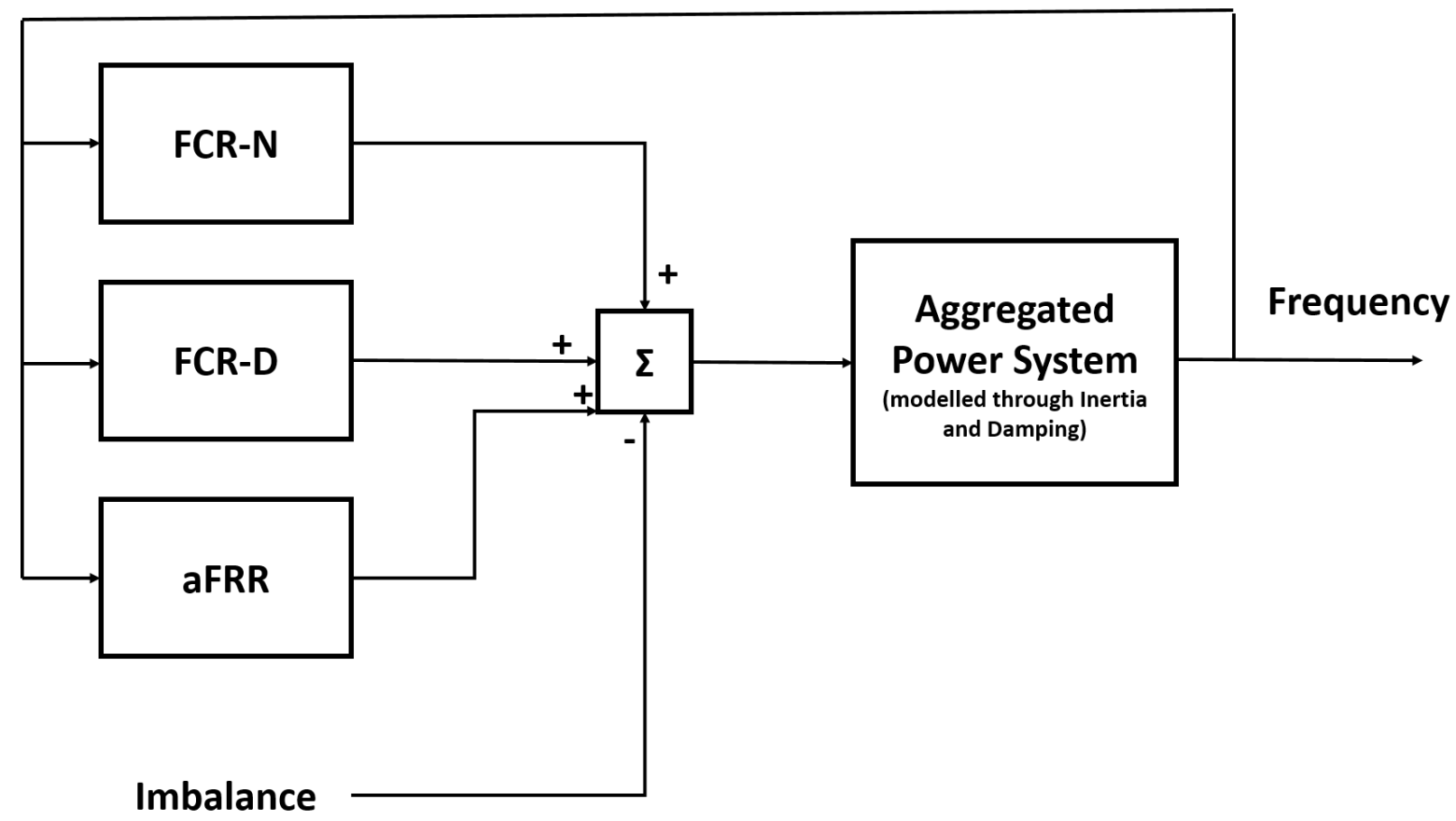

Fig. 3. Area Control-Dynamic Model of the Nordic synchronous area

Frequency

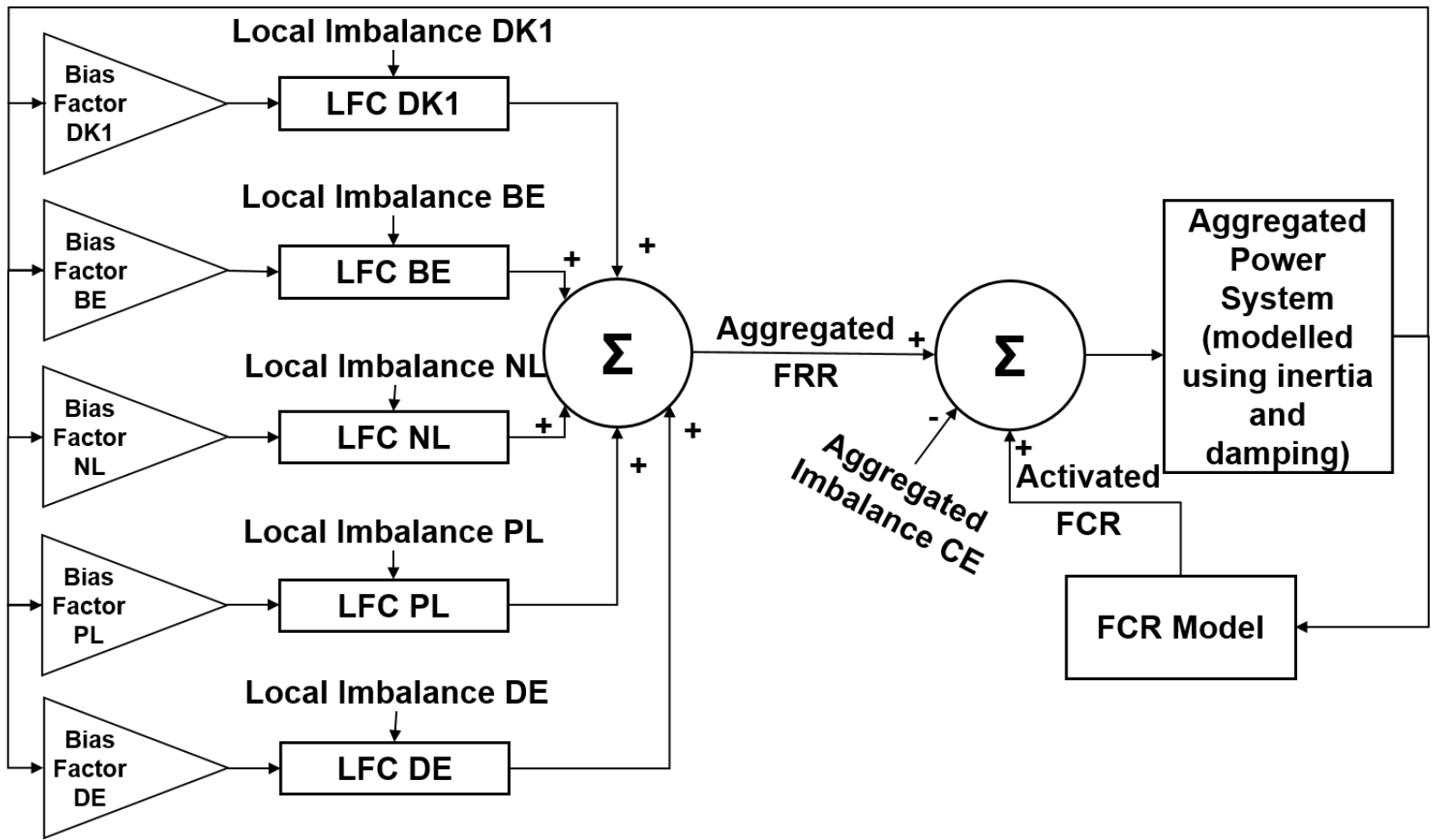

Fig. 4. Area Control-Dynamic Model of Continental Europe modelled through oad frequency controller (LFC) of North Sea countries Germany (DE), Poland (PL), the Netherlands (NL), Belgium (BE) and West Denmark (DK1) 
The Nordic network comprises of East Denmark (DK2), Norway (NO), Sweden (SE) and Finland (FI). In the Nordic network, there are frequency containment reserves separated between normal (FCR-N) and disturbance (FCR-D) for handling uncertainties and contingencies respectively. Additionally, limited volume of automatic frequency restoration reserves (aFRR) are also available (currently $200 \mathrm{MW}$ ), which is expected to increase in the future. Manual FRR (m-FRR) is used as balancing reserves and replenishing FRR and FCR. Aggregated power system is modelled with equation of motion using system inertia and system damping. It should be noted that system inertia and damping are always changing depending on the number of online conventional generations and loads and is updated based on the outcome of the previous sub-processes of the tool chain. Detailed dynamic models of the Nordic power system can be found in [24].

In the CE network, load frequency controller (LFC) of North Sea countries - Germany (DE), Poland (PL), the Netherlands (NL), Belgium (BE) and West Denmark (DK1) is modelled. LFC takes input of frequency deviation and area control error (or local imbalance in each control area). Bias factor is used to prioritize over area control to frequency deviation. Based on this copper plate model, all the LFCs activate FRR. Total activated FRR and activated FCR is used to mitigate frequency deviation of the power system modelled as equation of motion using inertia and damping. The detail of the dynamic models can be found in [23], [25].

\section{Case Studies- Assessment of large installation of OWPPs in North SEa towards}

\section{BALANCING OF NorThern EuROPEAN POWER SySTEMS IN 2030 AND 2050}

The DTU Balancing Tool Chain is used to assess balancing of Denmark when large number of OWPPs are installed in North Sea and connected to the neighboring countries. Two types of connections are studied - Project based and Offshore Grid. The project-based scenario includes only radial offshore connections of OWPPs to the onshore grid. On the contrary, the offshore grid scenario includes both radial and meshed offshore connections of OWPPs via hubs. These scenarios are developed for energy mix prognose of 2020, 2030 and 2050 [18]. Figure 5 shows the offshore grid scenario connection for 2030 and 2050 in North Sea along with transmission lines and hubs.

The cases to study are '2020', 'Offshore grid 2030', 'Offshore grid 2050', 'Project-based 2030' and 'Projectbased 2050' scenarios. The objective of this section is to compare all these scenarios in terms of power system balancing and provide recommendations on amount of balancing reserves required for the future as well as type of network that is preferable for balancing of the concerned power systems. These recommendations are mainly provided with respect to the Danish power system.

The total installed capacity of different fuels and technologies for the North Sea countries can be seen in Fig. 6. The scenarios come from investment optimisation done in Balmorel, as described in [18]. It can be seen that the total installed capacity increases until 2030 and there is a slight increase in 2050 scenarios. However, more interestingly, the proportion of coal and oil plants decreases substantially and is replaced by VRE (wind and solar), thereby, pronouncing the challenges for balancing process. The VRE and total non- $\mathrm{CO}_{2}$ generation proportions increase from $28 \%$ to $56 \%$ to $72 \%$ and $61 \%$ to $89 \%$ to $90 \%$ in 2020,2030 and 2050 respectively.

Increasing capacity of VRE sources can increase the uncertainty due to forecast error. Fig. 7 shows the probability density functions (pdf) of the Day-ahead wind power forecast error for each scenario in DK1. This forecast error is obtained as comparison between the output of OptiSpot and that of real-power production from 
2030

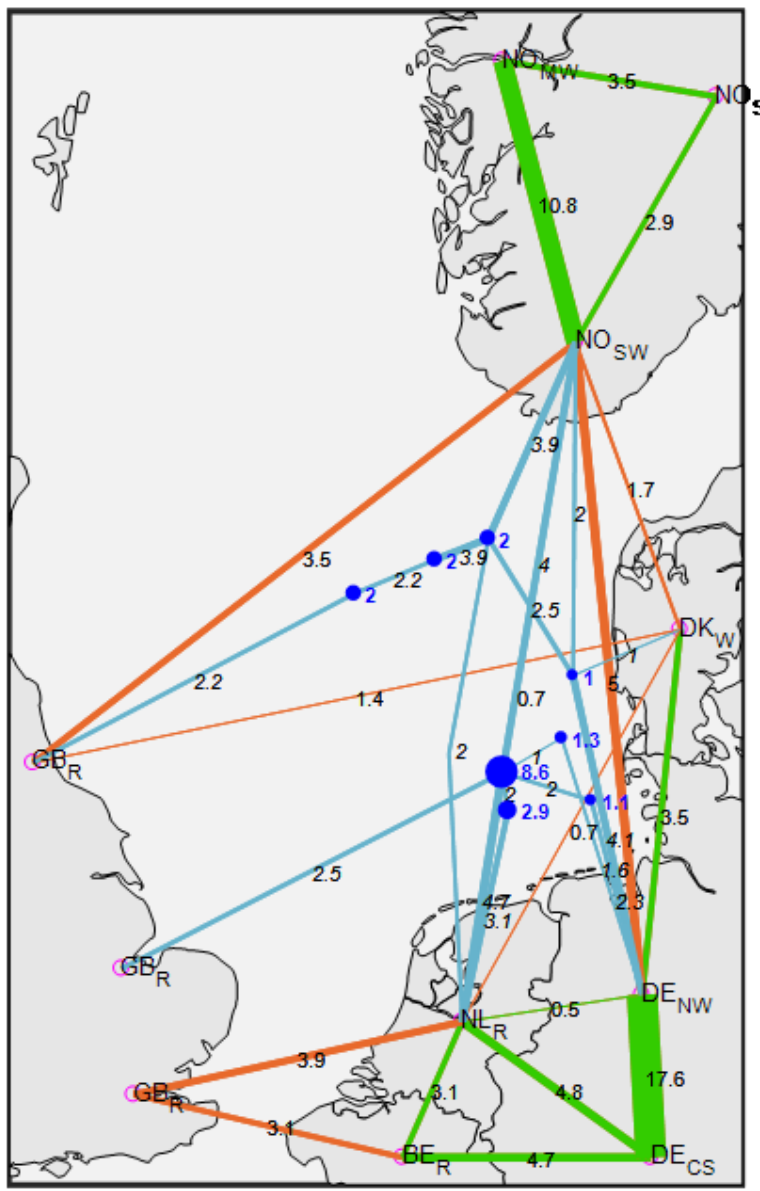

2050

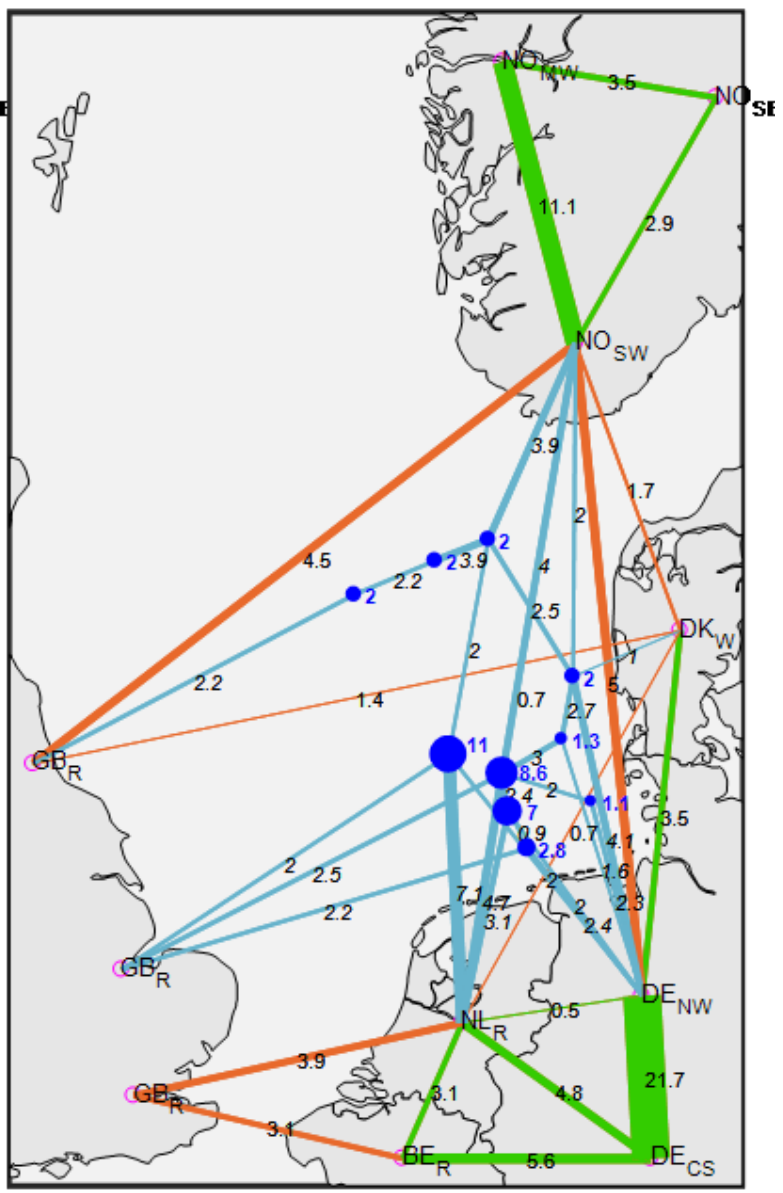

Fig. 5. Offshore grid scenario for 2030 and 2050 [18]. Onshore lines are shown in green, inter-country offshore connections in orange, lines related to the meshed grid in light blue and hub capacities in dark blue. The numbers denote GW.

wind. It can be seen that in the 2020 scenario, the forecast error varies between $\pm 5 \mathrm{GW}$, while the forecast error increases to around $\pm 10 \mathrm{GW}$ by 2030 and beyond. It should also be noted that the pdf has long tail with low probability. This implies that very high balancing resource is required for very few hours of the year. However, this information is not sufficient to infer whether those balancing reserves need to be available in DK1 or is already available in neighboring regions or fast balancing reserve sources such as gas turbines need to be procured. OptiBal is used to answer these questions. Also notice that there is not much difference between offshore-grid and project based scenarios.

Figure 8 exemplifies the Day-ahead market balancing process in DK1 and is shown for a day in each season for 2020, 2030 and 2050 for Offshore-based scenarios. Similar, results are obtained for project based scenarios as well. Electricity prices can also be observed in the figure. It can be observed that the total generation is generally higher than the demand (both exogenous and endogenous), showing that DK1 is exporting power to 


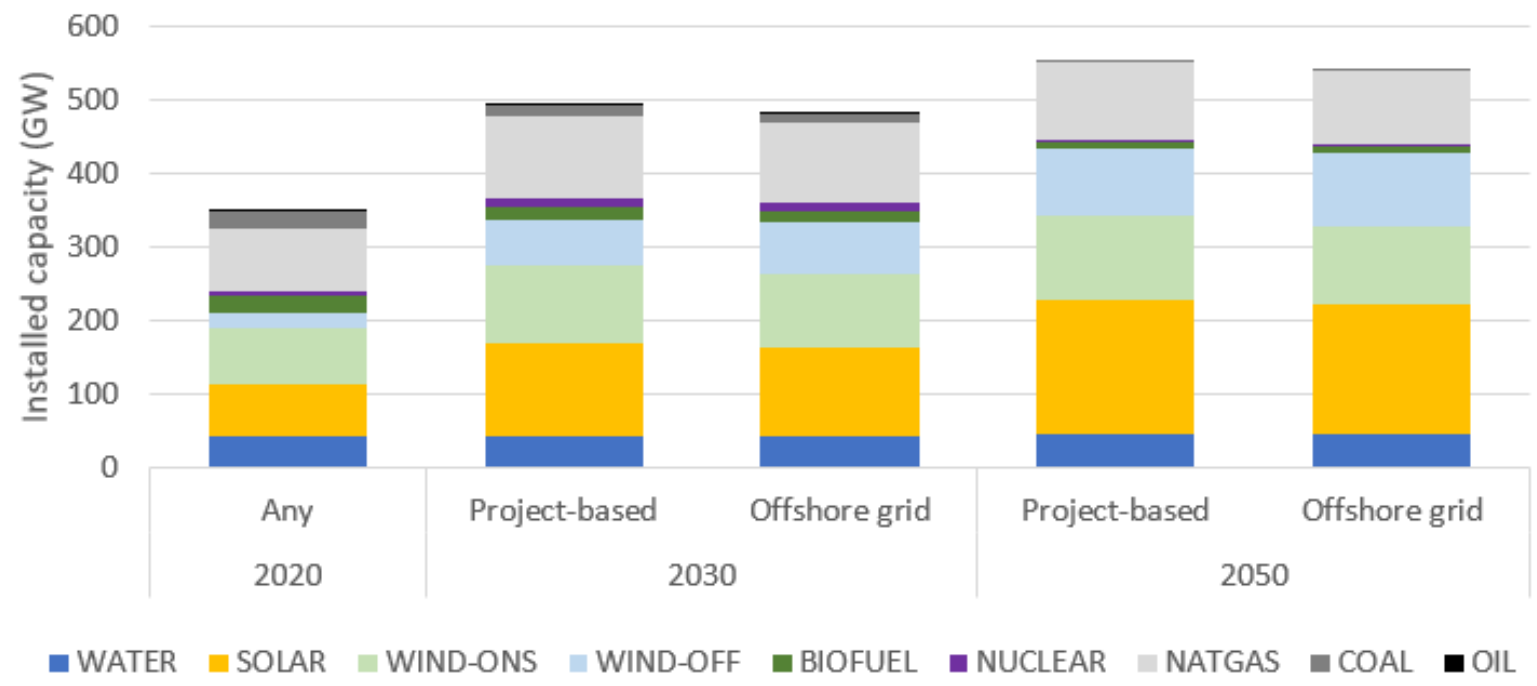

Fig. 6. Installed electricity capacity development per fuel and scenario in the countries in focus (GW).

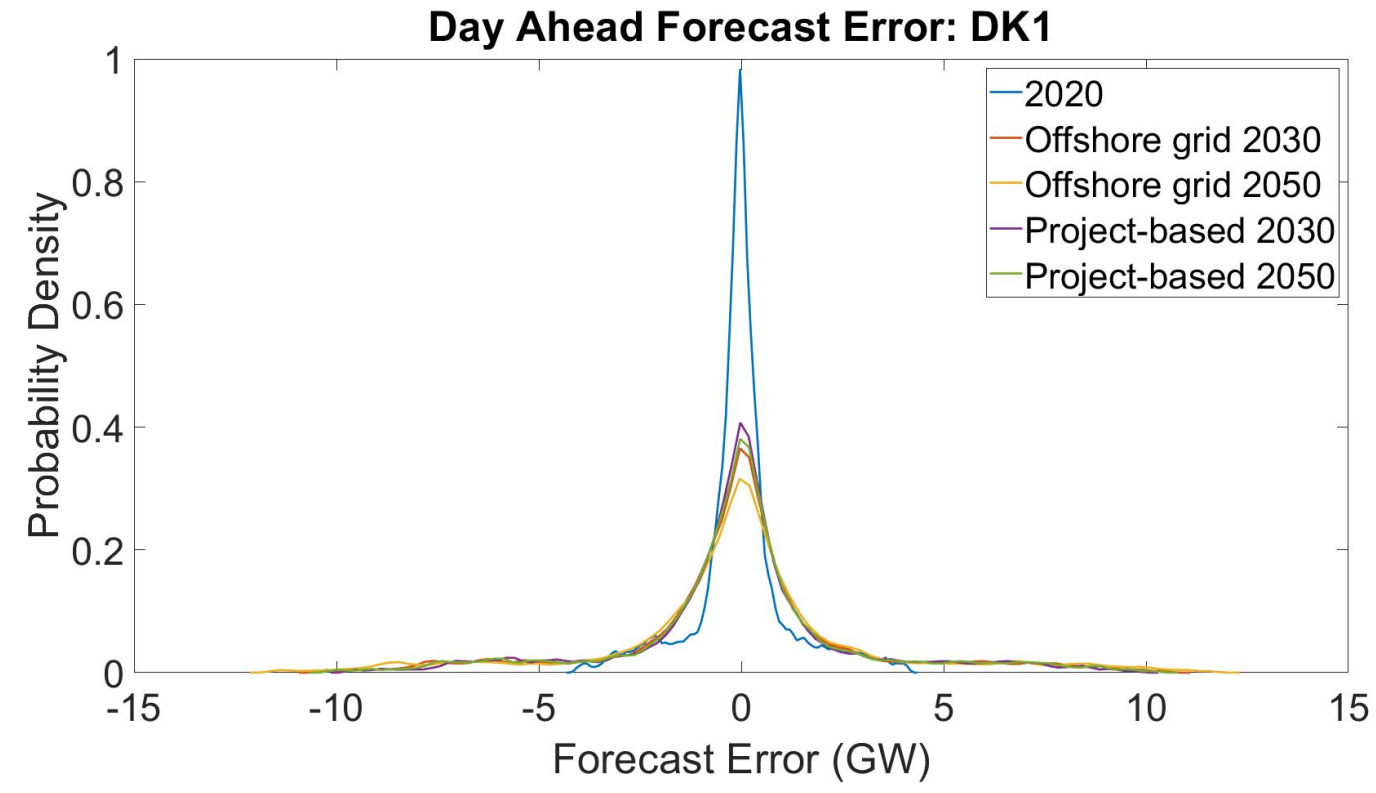

Fig. 7. Probability density of Day Ahead forecast error of DK1 control area for each scenario and year

the neighboring regions in those hours. It is also important to note that the conventional CHP generation is decreasing from 2020 to 2030 to almost negligible in 2050. In order to understand the impact of this, cumulative probability curve of total wind generation as proportion of internal demand in DK1 is shown in Fig. 9.

It can be seen from Fig. 9 that for $35 \%$ of the time wind power generation is more than $100 \%$ of the demand in 2020 and increases to 70-74\% beyond 2030. However, it is important to note that the offshore grid scenario allows for $4 \%$ higher number of hours when wind power generation is more than $100 \%$ of the demand for DK1 as compared to project based. The figure implies that Danish power systems are major exporter of energy, but the figure also has significance for balancing mechanism. With no or very low amount of conventional generators operating in the system, balancing responsibilities needs to fall on neighboring regions as well as 


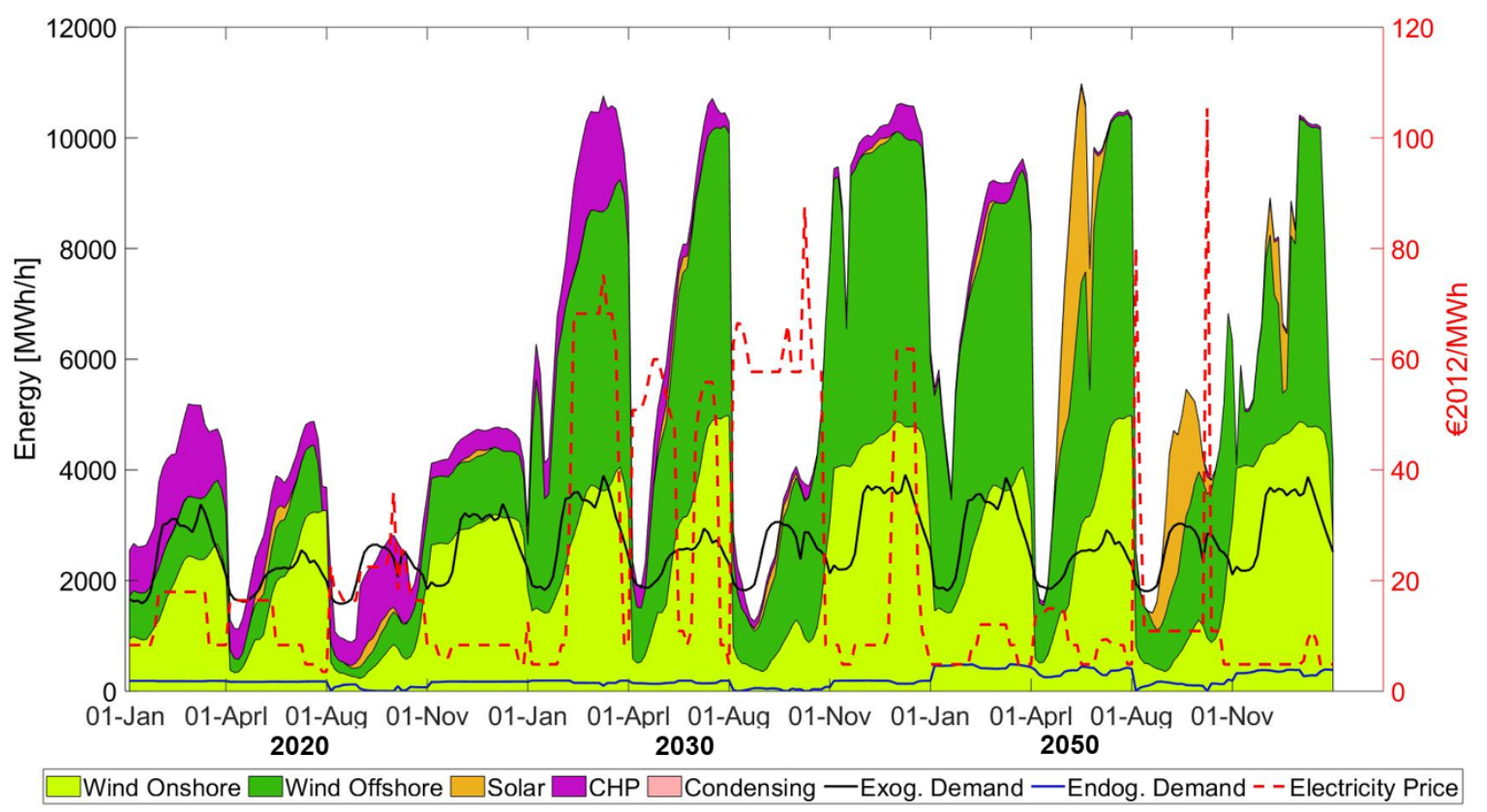

Fig. 8. Offshore grid scenario: Hourly dispatch and electricity prices for 4 representative days of each year in DK1

wind power plants and fast startup generators.

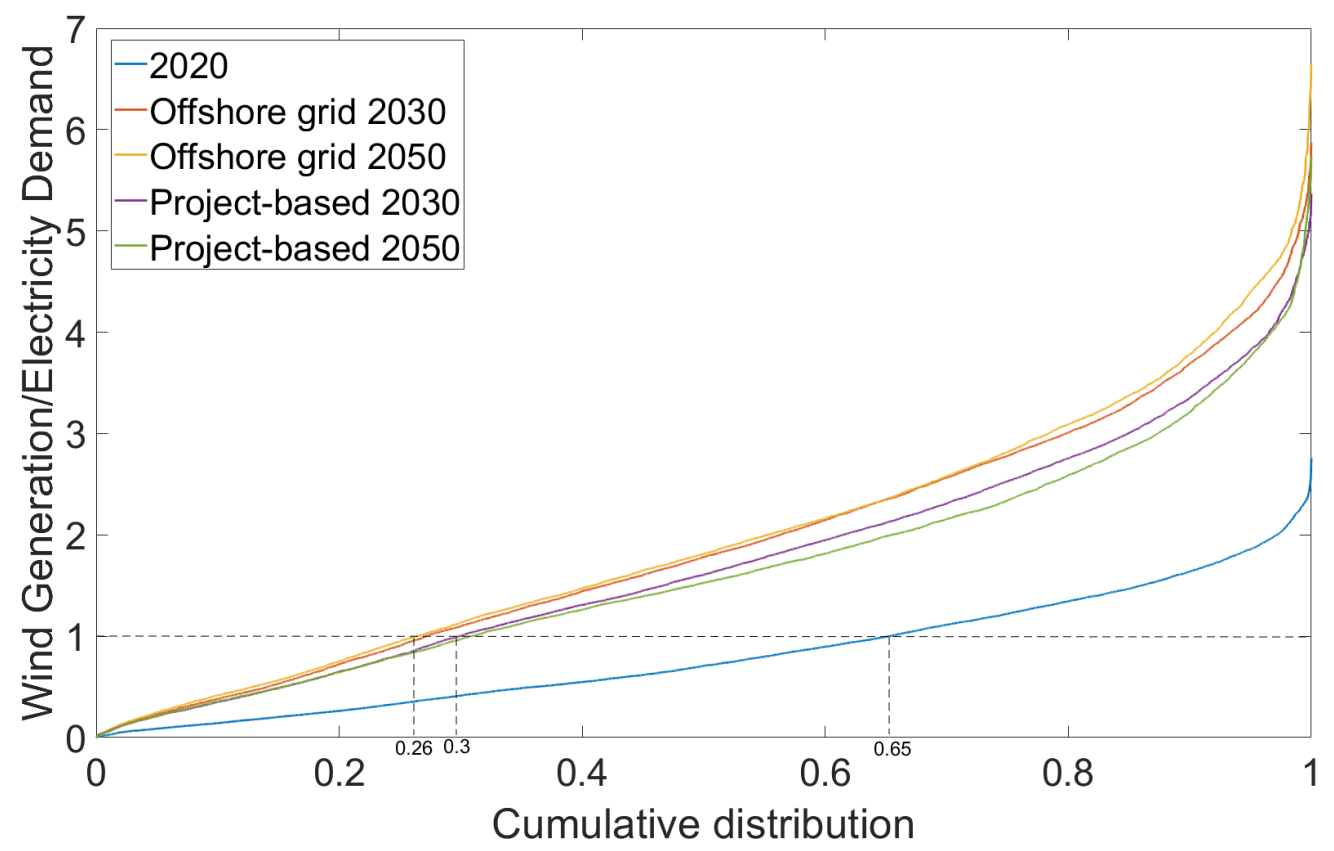

Fig. 9. Cumulative distribution of the instantaneous share of wind power generation in respect to demand for each scenario and year in DK1

The cumulative probability curves for the electricity prices for DK1 is shown in Fig. 10. There are three major observations: 1) average prices increase from 2020 to 2030 and decrease from 2030 to 2050, 2) the volatility of prices increases towards 2050, and 3) the prices in these regions are lower in the offshore grid scenario than 
in the project-based. This development is linked to the $\mathrm{CO}_{2}$ price assumptions and the penetration of VRE in the energy system. From 2020 to 2030, even though the penetration of VRE is large, the use of fossil fuels is still considerable and the $\mathrm{CO}_{2}$ price experiences a big increase (from $6 € / \mathrm{t} \mathrm{CO}_{2}$ to $76.7 € / \mathrm{t} \mathrm{CO}$ ), leading to increase of prices. Similar plots for all the neighboring regions also show similar trends as mentioned above. Due to transmission expansion, the average prices of the regions get closer to each other. Although the price in the regions in the different scenarios follow similar trends, their development is not identical. In the offshore grid scenario, the increase in average price from 2020 to 2030 is much higher in Norway (from $16.6 € / \mathrm{MWh}$ to $54.7 € / \mathrm{MWh}$ ) and DK1 (from 17.7 €/MWh to $57.9 € / \mathrm{MWh}$ ) than in Great Britain (from $35.6 € / \mathrm{MWh}$ to $59.4 € / \mathrm{MWh}$ ). Analogously, the decrease in average price from 2030 to 2050 follows the same pattern. In Norway, price decrease goes from $57.8 € / \mathrm{MWh}$ to $29.9 € / \mathrm{MWh}$, in DK1 price decreases from $57.9 € / \mathrm{MWh}$ to $37.9 € / \mathrm{MWh}$, and in Great Britain price decreases from $59.4 € / \mathrm{MWh}$ to $42.7 € / \mathrm{MWh}$.

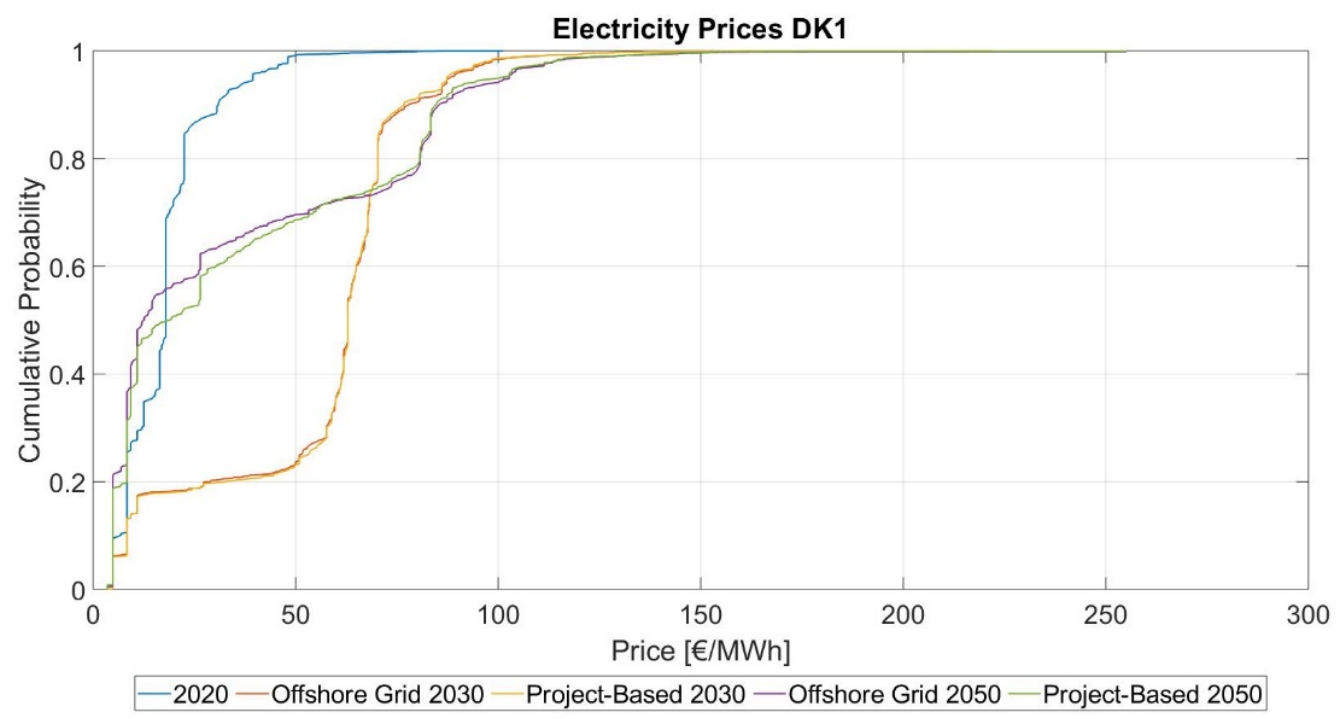

Fig. 10. Electricity Prices in DK1

An hour before the operation, hour-ahead prognosis of VRE is obtained. Hour-ahead (HA) forecasts of VRE are generally much lower than Day-ahead forecast error. Figure 11 shows the pdf curves for wind power HA forecast error for DK1. As compared to DA forecast errors in 7, HA forecast errors can be seen to be much lower - around $\pm 600 \mathrm{MW}$ in 2020 and $\pm 1.5 \mathrm{GW}$ in 2030 and beyond. Rest of the observations are similar to that of DA forecast errors in Fig. 7.

Considering the operational planning of the VRE from the day-ahead run, hour-ahead forecast error is computed with respect to Day-ahead forecast. Note, this is not same as hour-ahead forecast error, which is computed with respect to real-time power. Another imbalance arises from the conventional loads. In Day-ahead planning, these loads are scheduled as steps for each hour. Therefore, at every hour change, there is mismatch due to smoothness and continuity of the real loads. Using the hour-ahead VRE and load time series, the OptiBal cost-minimization re-dispatches the units so the energy balance is achieved. Since the time resolution used in the hour-ahead run is higher than in the day-ahead run, additional imbalance might take place due to limited 


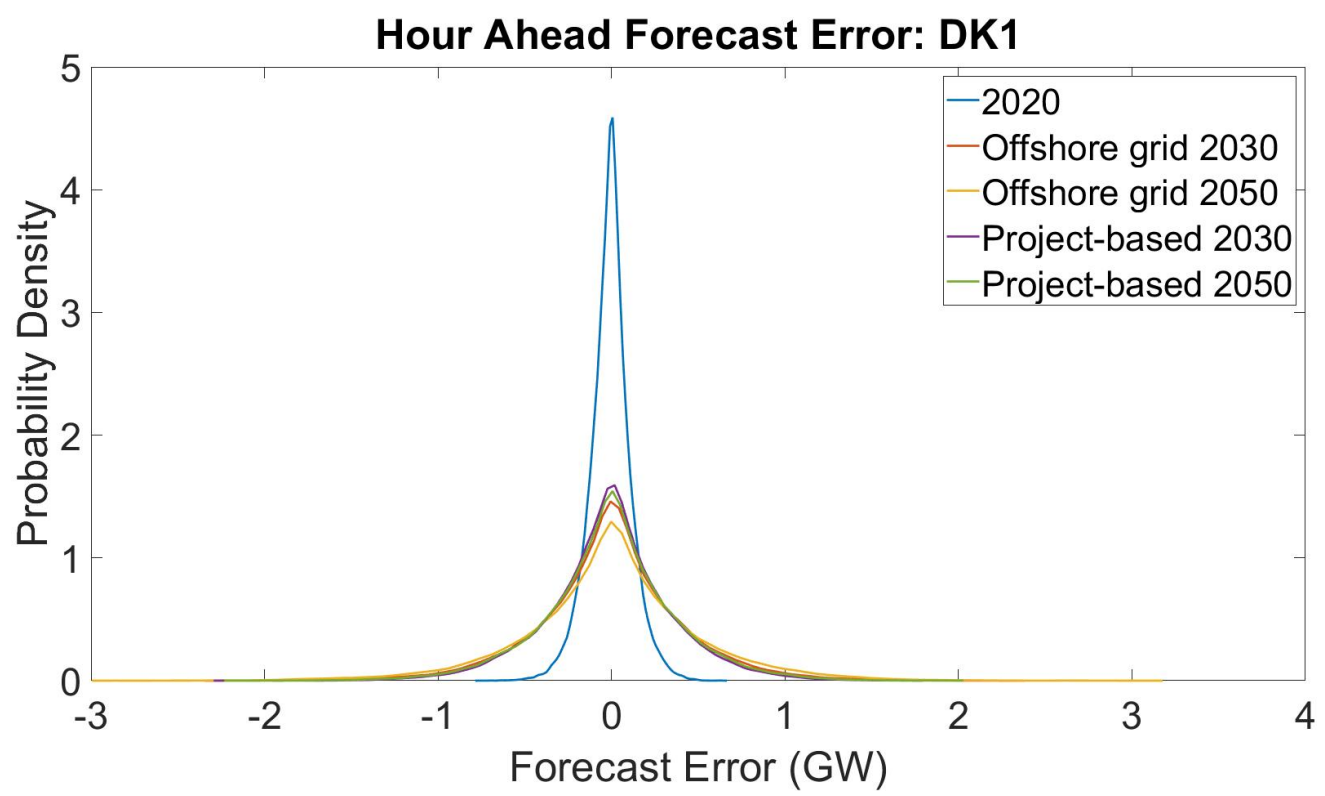

Fig. 11. Probability density of Hour Ahead forecast error of Denmark DK1 control area for each scenario and year.

ramping capabilities of the generators. Figure 12 shows the pdf curves for wind power hour-ahead forecast errors for DK1 region. Although there is increase in imbalance from 2020 values in 2030 and 2050, there is not much difference between project based and offshore grid based scenarios. This pattern is similar for all the regions. In order to compare all the regions, $5^{\text {th }}$ (p5) and $95^{\text {th }}$ (p95) percentiles of these pdfs are shown in Table I. p5 and p95 reflect the 95 percent of the times the negative and positive imbalances seen by the control area respectively. This also signifies that if the system operator can use this information similarly as done by Energinet, large volume of this imbalance can be reduced by activating balancing reserves and thereby, requiring less automatic reserves. It can also be noticed that in general, the positive imbalance is higher than that of negative imbalance. This can be attributed to that if the wind power generation is already curtailed in DA market, the negative imbalance with respect to DA would reduce. The imbalances in some areas such as $\mathrm{DE}$ is more for Offshore grid scenario as compared to project based scenario. This is due to the fact that in Offshore Grid scenario, the volume of installed wind power and therefore, wind power generation is slightly higher than that of project based. In all the areas, imbalances increase from 2020 to 2030 and further increased in 2050. However, the rate of increase varies from area to area, as it is dependent on the installed capacity of VRE as seen in Fig. 6.

OptiBal is used for minimization of the imbalances in all the areas based on Danish operational principle resulting in up regulation and down regulation of balancing reserves. Activated balancing reserves for up regulation and down regulation in DK1 is shown in Fig. 13 and Fig. 14 respectively. Denmark is heavily dependent on neighboring regions for balancing support. It has been observed that it is feasible to obtain support from neighboring regions, since the imbalances do not peak simultaneously in all the regions due to geographical smoothing effect of wind power. Moreover, it can be observed that technologies using Natural gas are dominating in terms of up and down activated balancing reserves until 2030. In contrary, in 2050 for both project-based and offshore grid scenario the contribution of wind power for up regulation during balancing is 


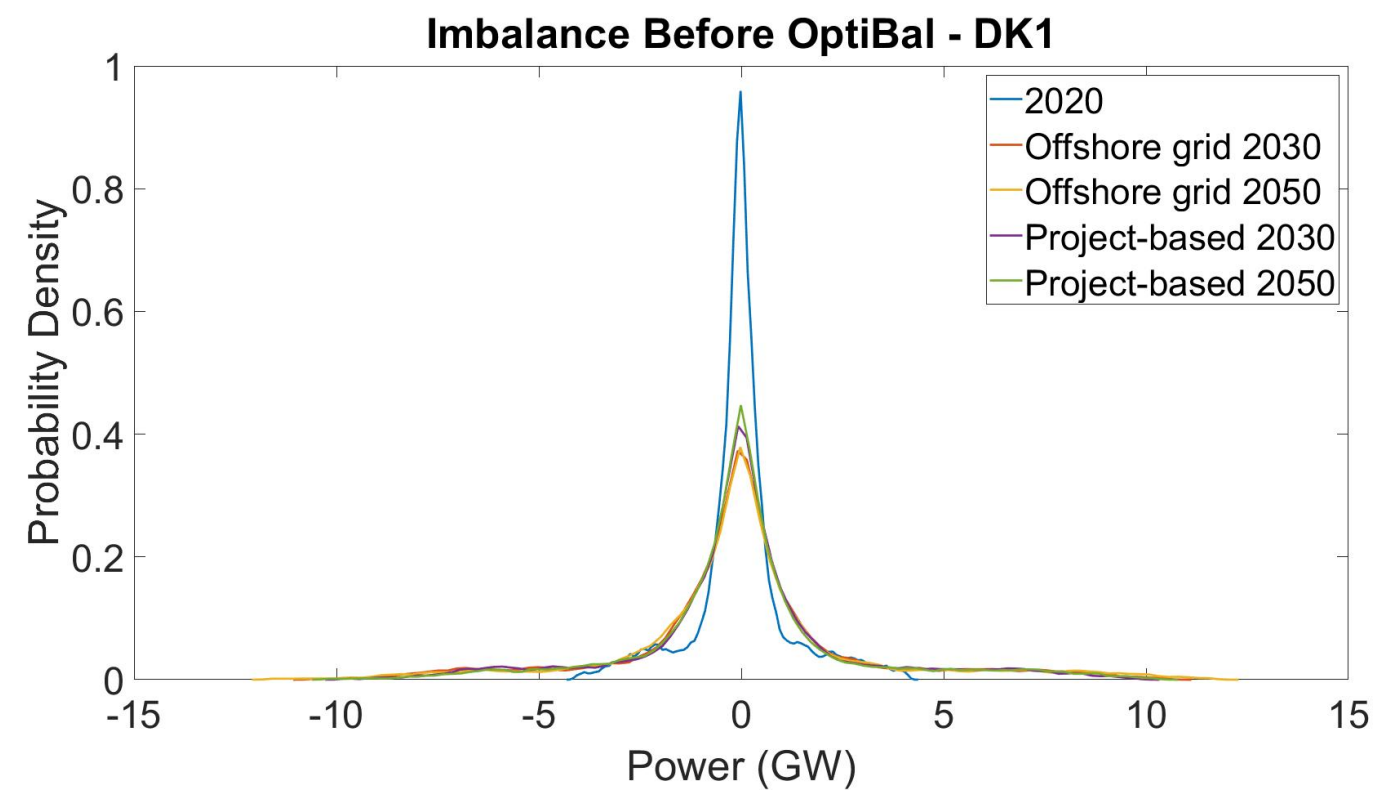

Fig. 12. Probability density functions of Hour Ahead Imbalance of DK1 control area for each scenario and year

TABLE I

$5^{\text {th }}$ AND $95^{\text {th }}$ PERCENTILE VALUE OF THE IMBALANCE IN GW BEFORE OptiBAL FOR EACH SCENARIO AND YEAR

\begin{tabular}{|c|c|c|c|c|c|c|c|c|c|c|}
\hline \multirow{3}{*}{ Area } & & & \multicolumn{4}{|c|}{ Offshore grid } & \multicolumn{4}{|c|}{ Project-based } \\
\hline & \multicolumn{2}{|c|}{2020} & \multicolumn{2}{|c|}{2030} & \multicolumn{2}{|c|}{2050} & \multicolumn{2}{|c|}{2030} & \multicolumn{2}{|c|}{2050} \\
\hline & p5 & p95 & p5 & p95 & p5 & p95 & p5 & p95 & p5 & p95 \\
\hline $\mathrm{BE}$ & -2.2 & 2.1 & -6.3 & 6.4 & -5.9 & 6.4 & -6.3 & 6.4 & -5.8 & 6.4 \\
\hline $\mathrm{DE}$ & -21.5 & 30.7 & -29.8 & 38.4 & -33.5 & 49.4 & -24.8 & 36.1 & -27.4 & 42.6 \\
\hline NL & -3.3 & 3.3 & -3.2 & 3.3 & -3.4 & 3.7 & -8.5 & 8.6 & -11.5 & 14.7 \\
\hline NO & -1.4 & 1.4 & -5.9 & 6.1 & -6.3 & 7.4 & -5.8 & 6.0 & -8.0 & 8.6 \\
\hline SE & -4.4 & 5.1 & -4.4 & 5.1 & -8.9 & 9.6 & -4.4 & 5.1 & -8.9 & 9.6 \\
\hline DK1 & -2.8 & 3.0 & -7.0 & 7.6 & -7.1 & 8.4 & -6.4 & 7.0 & -6.1 & 7.3 \\
\hline DK2 & -0.6 & 0.6 & -1.0 & 1.0 & -1.3 & 1.5 & -1.0 & 1.0 & -1.7 & 2.0 \\
\hline
\end{tabular}

$40 \%$ and $44 \%$ respectively. This has been possible since certain volume of wind power needs to be curtailed in the DA market. This is due to fact that total wind power generation is much higher than the load. However, total curtailed energy is not significantly high as compared to total annual energy production from wind power [26]. Regarding the balancing reserves activated for down regulation, the wind power in project-based and in offshore grid scenario contributes with $37 \%$ and $39 \%$ respectively. The role of wind power in future balancing of power system is optimistic for wind power development and possibility of new revenue stream for wind power plant owners. Energy transferred with neighbouring regions in order to procure balancing reserves can be found in [22]. It is interesting to observe that for up regulation in DK1 in 2050, DK1 is more dependent on neighbors in project based scenario as compared to offshore grid scenario, since total activated reserves in DK1 for offshore grid scenario is higher than project based scenario. While for down regulation, the differences are more pronounced in 2030 as compared to 2050, where more support from neighbors are required in offshore grid scenario as compared to project based scenario. 


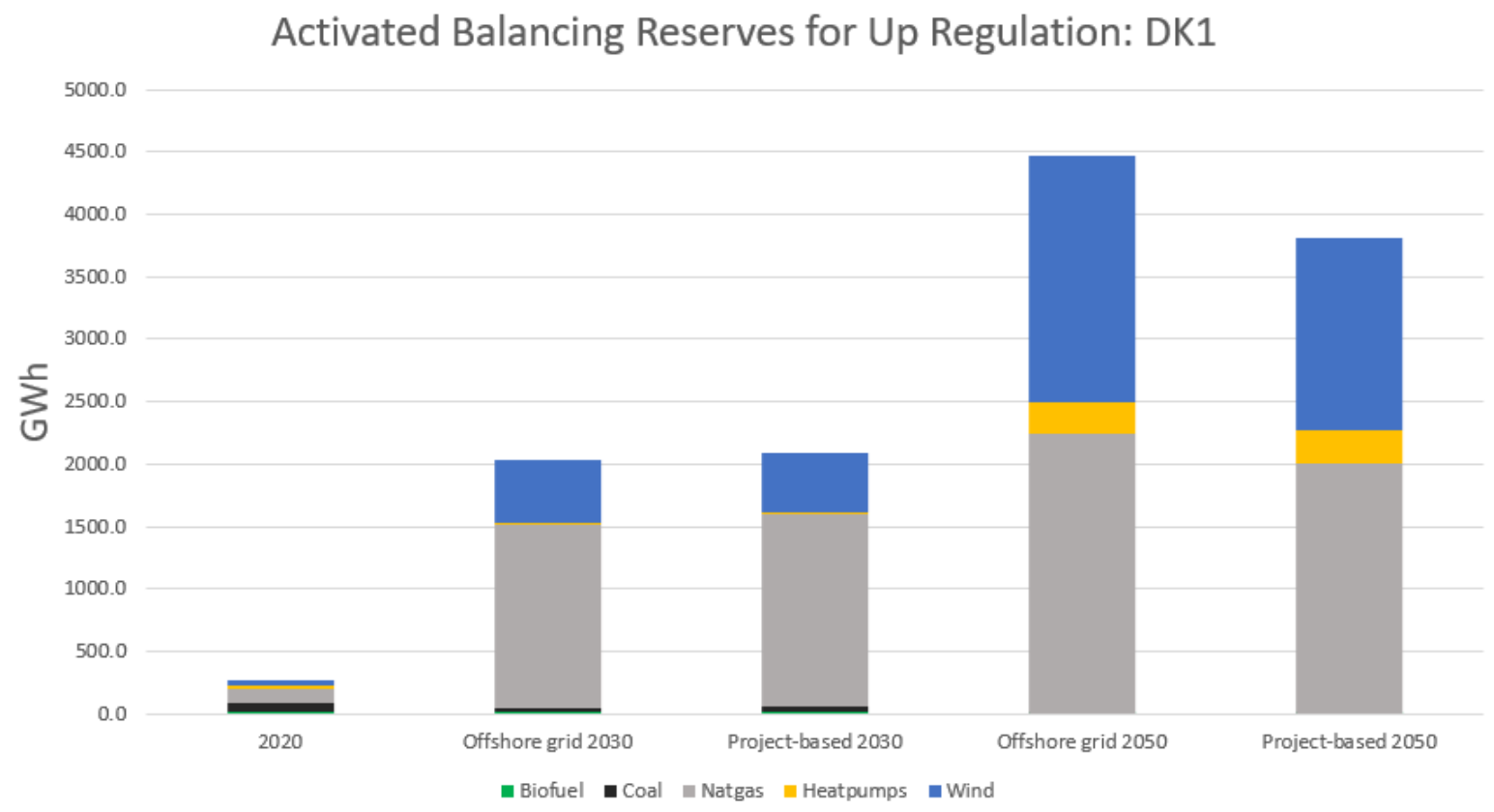

Fig. 13. Activated balancing reserves for up regulation in DK1 control area per scenario, year and technology

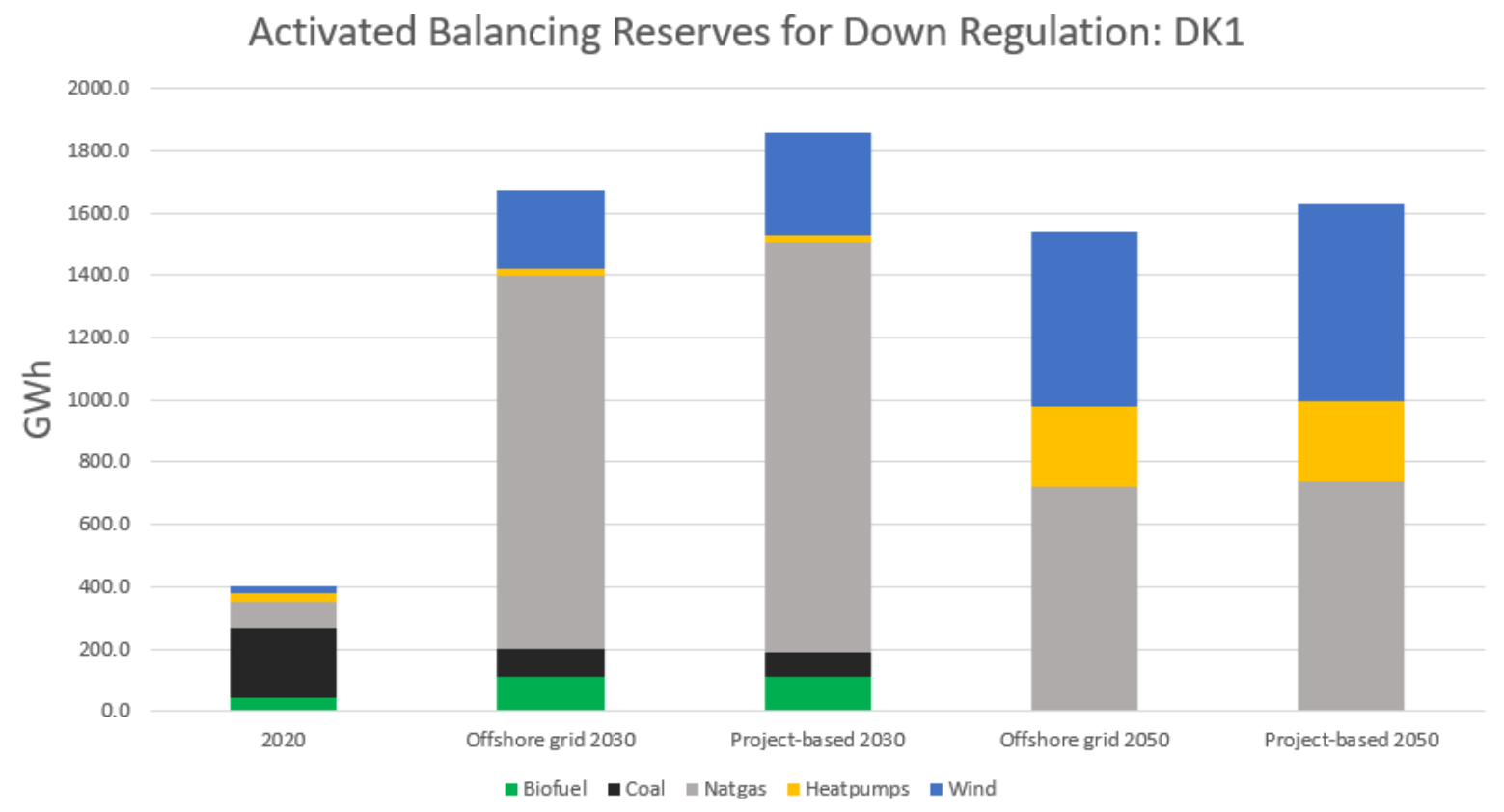

Fig. 14. Activated balancing reserves for down regulation in DK1 control area per scenario, year and technology

OptiBal also computes the up regulation and down regulation prices for each region. As discussed before, the electricity prices in all the regions increases until 2030 and reduces after that til 2050 based on CO2 assumption. Similar trend is also observed for up regulation and down regulation prices. The difference between offshore grid and project based scenarios are negligible. However, as expected, the cost of up regulation is higher than down regulation. 
TABLE II

AVERAGE PRICES FOR UP REGULATION AND DOWN REGULATION IN €2012/MWH FOR EACH SCENARIO AND YEAR

\begin{tabular}{c|c|c|c|c|c|c|c|c|c|c}
\hline \multirow{2}{*}{ Area } & \multirow{2}{*}{2020} & \multicolumn{4}{|c|}{ Offshore grid } & \multicolumn{4}{c}{ Project-based } \\
\cline { 2 - 11 } & \multicolumn{2}{|c}{202030} & \multicolumn{2}{|c}{2030} & \multicolumn{2}{c}{2030} \\
\cline { 2 - 10 } & up & down & up & down & up & down & up & down & up & down \\
\hline DE & 40.1 & 21.1 & 75.9 & 46.5 & 73.2 & 40.3 & 75.7 & 47.9 & 73.0 & 41.2 \\
NL & 47.5 & 35.5 & 72.2 & 47.7 & 71.5 & 39.2 & 74.2 & 51.0 & 73.6 & 44.3 \\
NO & 32.9 & 36.2 & 60.3 & 54.2 & 53.4 & 49.5 & 59.4 & 54.7 & 55.4 & 49.8 \\
SE & 37.9 & 29.9 & 63.4 & 47.2 & 74.5 & 47.3 & 63.3 & 47.0 & 73.4 & 47.5 \\
DK1 & 37.9 & 24.5 & 69.5 & 46.6 & 68.2 & 41.7 & 69.6 & 47.6 & 67.9 & 43.8 \\
DK2 & 36.6 & 23.7 & 69.2 & 48.5 & 68.8 & 44.9 & 70.4 & 49.6 & 68.6 & 45.4 \\
\hline
\end{tabular}

After activating balancing reserves using OptiBal, the remaining imbalance seen by each control area is mainly driven by HA forecast errors for VRE and loads and unforeseen contingencies. In this article, unforeseen contingencies are not considered and assumed that FCR is properly dimensioned to handle any unforeseen contingency. Rather, what is emphasised is the amount of automatic reserves that is required to meet forecast uncertainties thereby not utilizing the contingency reserves. Fig. 15 shows the pdfs for the real-time imbalance seen by DK1 following the balancing reserves deployed based on OptiBal output. It can be seen that this imbalance is approx. $\pm 400 \mathrm{MW}$ in 2020 and approx. $\pm 1 \mathrm{GW}$ in 2030 and beyond with long tails and low probabilities. This calls for a probabilistic dimensioning of FRR.

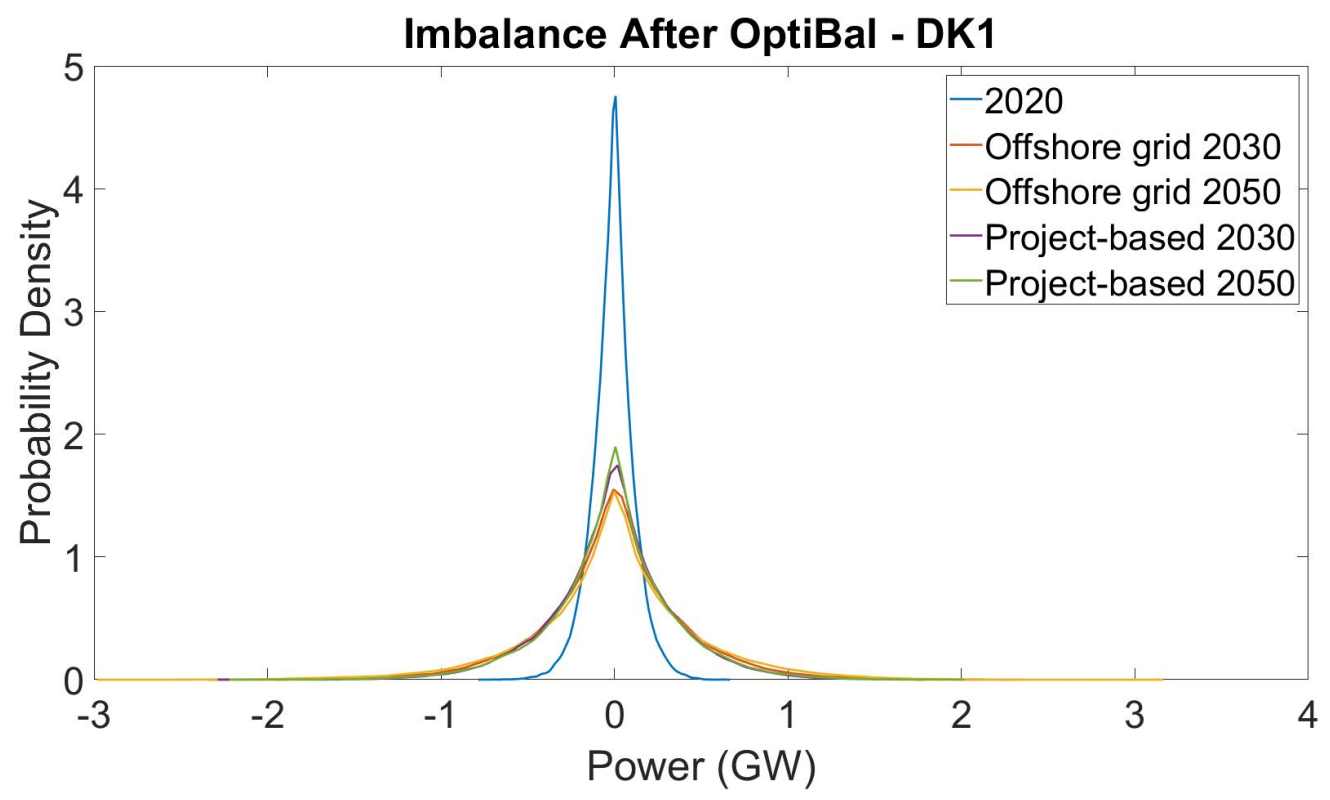

Fig. 15. Probability density functions of Real Time Imbalance of DK1 control area for each scenario and year.

There are different methods of dimensioning for FRR as defined in UCTE's operation handbook differ among the control areas based on different operational needs [27]. In this article, the Probabilistic Sizing Approach is used, where the minimum value for the sum of FRR capacity and replacement reserve capacity is defined as the 99\% quantile of the yearly imbalance [28]. Probablistic estimation of FRR can be seen in Table III. It can 
be observed that the FRR requirements in most of the regions increase by many folds in 2030 as compared to 2020. The increase in BE is about 4 times, DE is 1.3 times, DK1 is 3 times and in Nordic by 3 times. However, increase from 2030 to 2050 is mainly pronounced in DE among the areas presented in Table III. It is also interesting to note that the amount of FRR required is more in CE areas for Offshore grid scenario as compared to Project based scenario while in Nordic network, the increase in FRR is more for project based scenario.

TABLE III

ESTIMATION OF FRR FOR EACH SCENARIO AND YEAR

\begin{tabular}{c|c|cc|cc}
\hline & & \multicolumn{2}{|c|}{ Offshore grid } & \multicolumn{2}{c}{ Project-based } \\
Control \& Synchronous Areas & 2020 & 2030 & 2050 & 2030 & 2050 \\
\hline BE & 0.5 & 1.9 & 1.9 & 1.9 & 1.9 \\
DE & 3.1 & 4.3 & 5.7 & 3.5 & 4.6 \\
DK1 & 0.4 & 1.3 & 1.5 & 1.1 & 1.1 \\
Nordic & 0.5 & 1.4 & 1.6 & 2.1 & 3.5 \\
\hline
\end{tabular}

Dynamic modelling of the area and frequency control is fed with the real-time imbalance computed for each control area. As mentioned before, power system is modelled through inertia and damping of the power system. However, since inertia of the power system changes always depending on the operating generation mix. The lower the system inertia, the faster the rate of change of frequency is. Since, CE is a large power system, the inertia of the system is not deteriorated by 2050 , however, the inertia of the Nordic can be seen deteriorating in future. Figure 16 shows the inertia of the Nordic power system. The bimodality of the curves is very interesting to note and shows that the Nordic power system is either expected to have high inertia or low inertia. Although, the inertia reduces slightly by 2030, there is large decrease in inertia (even to less than 1MWs/MVA) by 2050 .

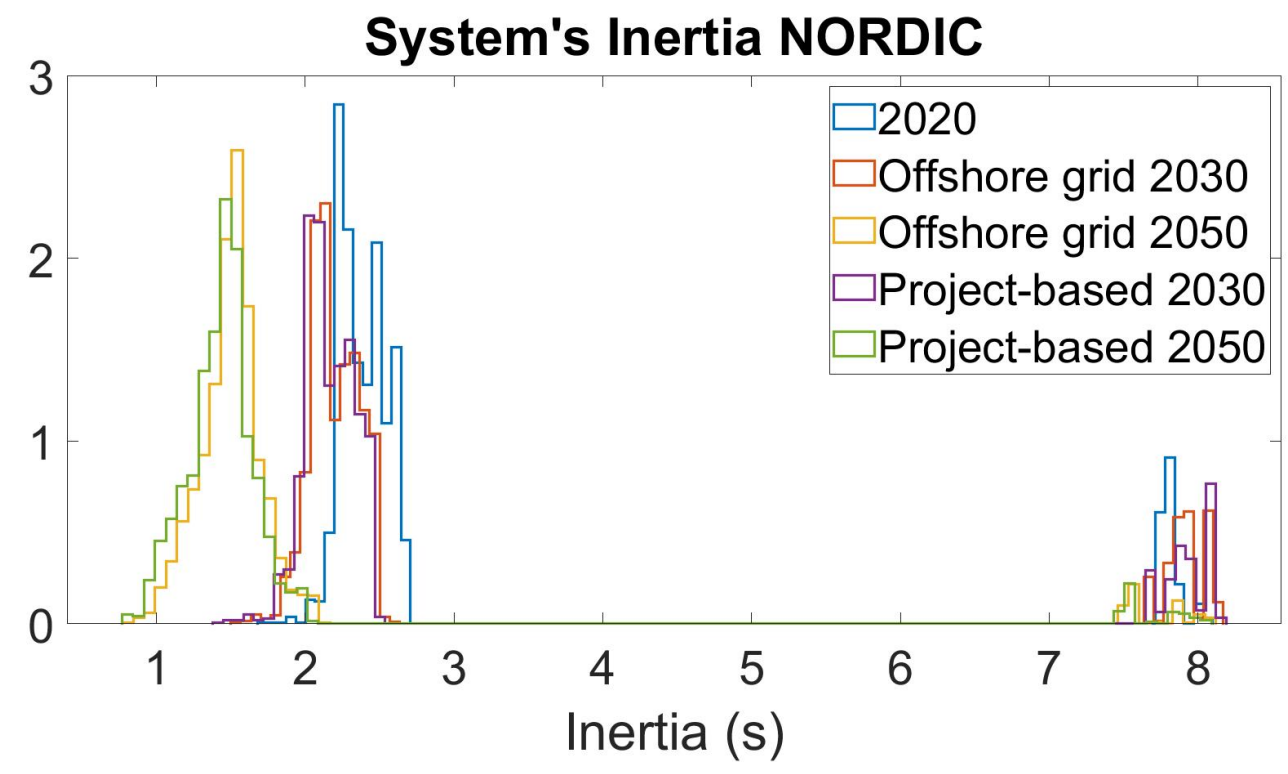

Fig. 16. Normalised Histogram of system inertia in Nordic synchronous area for each scenario and year.

Frequency quality is assessed following activation of FCR and FRR to meet the real-time imbalance created 
due to the VRE uncertainty. The frequency quality is measured as the number of hours per year when the frequency is outside the nominal range ( $\pm 50 \mathrm{mHz}$ in CE and $\pm 100 \mathrm{mHz}$ in Nordic network) as shown in Table IV. It can be seen that frequency goes beyond nominal for very few hours per year, so the control and estimated volume of FRR can be assumed satisfactory. However, FCR has also been activated to receive this frequency quality. Table shows the $5^{\text {th }}$ and $95^{\text {th }}$ percentile of the activated FCR for different scenarios. It can be seen that the increase in FCR is not substantially more for CE in 2030 and 2050 as compared to 2020. Although, FCR activation increases in Nordic by 4 times of the value of 2020 in 2050 scenario; however, the increase in FCR is not excessively high as compared to dimensional fault.

TABLE IV

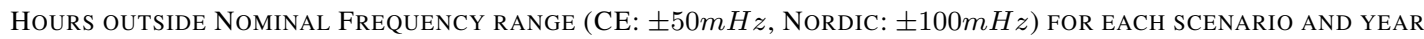

\begin{tabular}{c|c|c}
\hline Scenarios & CE & Nordic \\
\hline 2020 & 12.5 & 0.9 \\
Project-based 2030 & 16.8 & 13.6 \\
Offshore grid 2030 & 16.8 & 16.8 \\
Project-based 2050 & 23.4 & 35.6 \\
Offshore grid 2050 & 31.2 & 22.0 \\
\hline
\end{tabular}

\section{CONCLUSION}

With increasing share of variable renewable energy sources in the power systems, balancing of the power system becomes challenging. Balancing process involves multiple sub process incorporating day-ahead market, balancing market, area control and frequency control. All these processes should not be treated separately but should be treated together. In this direction, balancing tool chain can be very useful. This article discusses the salient features of such a balancing tool chain. DTU balancing tool chain is introduced and described. The value of the balancing tool chain is emphasized through case studies on European power system scenario on 2020, 2030 and 2050 with focus on North Sea countries.

The DTU balancing tool chain provides recommendations for future North Sea countries with large share of wind power installed in North Sea in terms of market operation and balancing requirements.

It has been observed that forecast uncertainty from variable renewable energy such as wind power can create large volume of imbalance in these countries in future scenarios. This is especially challenging for balancing the power system especially when it is windy.

Denmark is expected to have wind power generation more than $100 \%$ of its demand in 2030 by $70-75 \%$ making it a major exporter to the neighboring countries. The electricity prices are expected to increase til 2030 and start reducing after that owing to a combination of the $\mathrm{CO} 2$ price and the amount of fossil generation in the system. Offshore grid scenario allows for more power generation as compared to project based scenario.

Hour ahead balancing has a major role to play in these future power systems.The majority of the imbalance due to forecast uncertainties can be reduced by hour ahead balancing. Hour ahead imbalances increases many folds in all the areas, however, there is not much difference between project based and offshore grid scenarios. Therefore, offshore grid scenario can be preferable to project based scenario, since it provides higher reliability 
to the power system. Hour ahead balancing uses natural gas technologies in Denmark mainly for up and down regulation, but wind power also plays a major role in hour ahead balancing in 2030 and 2050 scenarios.

Frequency restoration reserves is mainly utilized for reducing remaining real-time imbalances. In this direction, probabilistic dimensioning of frequency restoration reserves is strongly advised. It is to be noted that this dimensioning is additional to the frequency restoration reserves allocated for contingencies. With proper dimensioning of frequency restoration reserves, frequency quality can be expected to be acceptable in future scenarios.

The balancing tool chain has many more applications which can be valuable for future research. Impact of wakes and blockage effects on power system balancing especially with large volume of wind power can be studied with this balancing tool chain. Assessment of impact of proposed North Sea island on power system balancing can be done. Value of balancing of individual wind power plants through portfolio management as opposed to balancing the uncertainty of whole system can be performed.

\section{ACKNOWLEDGEMENTS}

The authors acknowledge support from the NSON-DK project funded by EUDP (grant 64018- 0032; previously ForskEL).

\section{REFERENCES}

[1] European Commission, “2050 long-term strategy," https://ec.europa.eu/clima/policies/strategies/2050_en\#tab-0-0.

[2] K. Uhlen, S. Jaehnert, C. Hamon, C. Bruno, H. Farahmand, T. Inoue, J. Matevosjana, F. Nobel, and P. E. Sørensen, "Analytical techniques and tools for power balancing assessments," 2016, Technical Report, Working Group-C4.603.

[3] DNV GL, "KERMIT power balancing in energy storage," https : / / www . dnvgl . com / services / kermit-power-balancing-in-energy-storage- 153109.

[4] C. Sabelli, G. Giannuzzi, C. Martarelli, M. A. Sidoni, M. Pozzi, C. Bruno, D. Dresco, and D. Di Bernardo, "Very short-term optimal dispatching: An integrated solution for the advance dispatching," in 44th International Conference on Large High Voltage Electric Systems. CIGRE, 2012.

[5] N. P. Padhy, "Unit commitment-a bibliographical survey," IEEE Transactions on power systems, vol. 19, no. 2, pp. 1196-1205, 2004.

[6] B. H. Chowdhury and S. Rahman, "A review of recent advances in economic dispatch," IEEE transactions on power systems, vol. 5, no. 4, pp. 1248-1259, 1990.

[7] F. Wiese et al., "Balmorel open source energy system model," Energy Strategy Reviews, vol. 20, pp. 26-34, 2018, doi: https: //doi.org/10.1016/j.esr.2018.01.003.

[8] H. Larsen, "Wilmar planning tool. vba documentation," 2006, WILMAR Deliverable D6.2(e), Risø-R-1553(EN).

[9] Energinet, "SIFRE: Simulation of Flexible and Renewable Energy sources," https : / / energinet . dk / - / media / 0C7AA9C78EBE428580CAB85E120129CB.pdf.

[10] A. B. Hansen, A. Orths, K. Falk, and N. K. Detlefsen, "Danish fossil independent energy system 2050: from strategic investigations to intra-hour simulation of balancing issues," in Proceedings of the 10th international workshop on large-scale integration of wind power into power systems, Aarhus, Denmark, 2011.

[11] P. Kanellas, K. Das, P. E. Sørensen, and J. Gea-Bermudez, "Modelling the intra-hour power system balancing of the danish power system for 2020, 2030 and 2050," in 18th Wind Integration Workshop, 2019.

[12] K. Das, M. Litong-Palima, P. Maule, M. Altin, A. D. Hansen, P. E. Sørensen, and H. Abildgaard, "Adequacy of frequency reserves for high wind power generation," IET Renewable Power Generation, vol. 11, no. 8, pp. 1286-1294, 2016.

[13] A. Mileva, J. Johnston, J. H. Nelson, and D. M. Kammen, "Power system balancing for deep decarbonization of the electricity sector," Applied Energy, vol. 162, pp. 1001-1009, 2016.

[14] K. Das, F. Guo, E. Nuño, and N. A. Cutululis, "Frequency stability of power system with large share of wind power under storm conditions," Journal of Modern Power Systems and Clean Energy, vol. 8, no. 2, pp. 219-228, 2020. 
[15] M. Koivisto et al., "Using time series simulation tool for assessing the effects of variable renewable energy generation on power and energy systems," Wiley Interdisciplinary Reviews: Energy and Environment, p. e329, 2019.

[16] M. Koivisto, K. Plakas, E. R. H. Ellmann, N. Davis, and P. Sørensen, "Application of microscale wind and detailed wind power plant data in large-scale wind generation simulations," Electric Power Systems Research, vol. 190, p. 106638.

[17] M. Koivisto, G. M. Jónsdóttir, P. Sørensen, K. Plakas, and N. Cutululis, "Combination of meteorological reanalysis data and stochastic simulation for modelling wind generation variability," Renewable Energy, pp. 991-999, 2020.

[18] M. Koivisto, J. Gea-Bermúdez, and P. Sørensen, "North sea offshore grid development: Combined optimization of grid and generation investments towards 2050," IET Renewable Power Generation, p. 114702, 2020.

[19] M. M. Pedersen, P. van der Laan, M. Friis-Møller, J. Rinker, and P.-E. Réthoré, "Dtuwindenergy/pywake: Pywake,” Feb 2019.

[20] L. Söder, "Simulation of wind speed forecast errors for operation planning of multiarea power systems," in 2004 International Conference on Probabilistic Methods Applied to Power Systems. IEEE, 2004.

[21] J. Gea Bermúdez, K. Das, M. J. Koivisto et al., "Operational planning of large-scale energy systems with high share of renewable generation," 2020, https://www.techrxiv.org/articles/Operational_planning_of_large-scale_energy_systems_with_high_ share_of_renewable_generation/12465230/files/23086619.pdf.

[22] P. Kanellas, K. Das, J. Gea-Bermudez, and P. Sørensen, "Balancing tool chain: Balancing and automatic control in north sea countries in 2020, 2030 and 2050," 2020, https://backend.orbit.dtu.dk/ws/files/210203455/NSON_Report_D3_2.pdf.

[23] K. Das, Integration of renewable generation in power system defence plans. DTU Wind Energy, 2016.

[24] E. F. Sichani, "Frequency control in future nordic power system with high penetration of wind power," 2017, master Thesis, DTU Wind Energy-M-0146.

[25] J. J. Grainger, W. D. Stevenson, W. D. Stevenson et al., Power system analysis, 2003.

[26] J. Gea-Bermúdez, K. Das, L.-L. Pade, M. Koivisto, and P. Kanellas, "Nson-dk day-ahead market operation analysis in the north sea region towards 2050," 2019.

[27] Handbook, UCTE Operations, "P1-policy 1: Load-frequency control and performance [c]," 2009, ”https://www.entsoe.eu/fileadmin/ user_upload/_library/publications/entsoe/Operation_Handbook/Policy_1_final.pdf”.

[28] ENTSO-E, "Network code on load frequency control and reserves (lfcr)," 2013, "https://www.entsoe.eu/major-projects/ network-code-development/load-frequency-control-reserves/Pages/default.aspx". 